\title{
The effect of intralist similarity on serial anticipation and free recall
}

\author{
RONALD RAY SCHMECK \\ Southern Illinois University, Carbondale, Ill. 62901 •
}

This study was designed to investigate the effects of intralist similarity within serial-anticipation and free-recall paradigms, using a factorial design. It was hoped that, by keeping the procedures and material as similar as possible within the two paradigms, the study would provide a comparison of learning within each of the paradigms and replicate intralist similarity effects previously demonstrated in separate experiments. The results indicated that high intralist similarity interfered with serial learning but had no statistically significant effect within the free-recall paradigm. Further, the free-recall paradigm produced superior learning only when the intralist similarity was high. The relationship between these results and those reported by Horowitz (1961) is discussed.

Several studies (e.g., Underwood, 1952) have demonstrated that serial learning varies as an inverse function of intralist similarity. On the other hand, other studies (e.g., Deese, 1959) indicate that free recall is improved by increased intralist similarity. One attempt to resolve this conflict was that of Horowitz (1961). The latter study employed two lists of trigrams, composed by arranging either 4 or 12 different letters to form 12 CCCs. The Ss were run for 10 trials while either freely recalling the items or recalling them in the same order in which they were presented. The results indicated that high similarity aided free recall but hindered ordering. The present study was designed in an attempt to replicate the results of the Horowitz study while using a traditional serial-anticipation procedure rather than the ordering procedure employed by Horowitz (1961).

SUBJECTS AND DESIGN

Twenty volunteers from the introductory psychology courses at Southern Illinois University were employed as Ss. The Ss were assigned randomly to one of four groups in order to vary similarity and learning paradigm in a 2 by 2 factorial design. The groups were: high

Table 1

Mean Number of Syllables Recalled During a 10-Trial Session

\begin{tabular}{lll}
\hline \multirow{2}{*}{\multicolumn{1}{c}{ Method }} & \multicolumn{2}{c}{ Similarity } \\
\cline { 2 - 3 } \multicolumn{1}{c}{ High } & Low \\
\hline Serial Anticipation & 64.8 & 85.4 \\
Free Recall & 89.2 & 78.2 \\
\hline
\end{tabular}

similarity/serial anticipation, low similarity/serial anticipation, high similarity/free recall, and low similarity/free recall.

\section{APPARATUS AND PROCEDURE}

Both the high- and low-similarity lists consisted of 10 syllables (CVCs). The high-similarity list was composed by arranging 7 letters to form 10 CVCs. The low-similarity list was composed by arranging 25 letters to form the $10 \mathrm{CVCs}$. The lists were presented on a Hull-type memory drum (Lafayette Instrument Company, Model 303c), using a $2 \frac{1}{2}$-sec presentation interval. In the serial anticipation condition, Ss were given one study trial and then instructed to anticipate the next item each time an item was presented. They were instructed to respond by spelling the succeeding item. In order to make the free-recall procedure similar to the serial-anticipation procedure a paced-recall technique was employed. Ss were given one study trial and then instructed to attempt to recall one of the CVCs each time $E$ tapped his pencil on the table. The cue was presented every $2 \frac{1}{2} \mathrm{sec}$, and the Ss were told that the items could be recalled in any order. As in the above procedure, the syllables were presented on the memory drum with a $2 \frac{1}{2}-\mathrm{sec}$ presentation interval, and Ss were instructed to spell the syllables when responding. In both conditions Ss were given 10 trials. The measure recorded was the total number of items recalled during the 10-trial session.
RESULTS AND DISCUSSION

The results of the experiment are summarized in Table 1. Analysis of variance indicated that neither the overall effects of learning method nor similarity were statistically significant. However, the interaction was highly significant, $F(1,16)=6.44, p<.025$. In the serial-anticipation condition, a significantly greater number of syllables were correctly recalled when intralist similarity was low, $\mathrm{F}(1,16)=7.68, \mathrm{p}<.025$. This result is in agreement with that of Horowitz (1961). However, turning next to the effects of similarity in the free-recall condition, the analysis indicated that this difference was not significant, $F(1,16)=1.56$. The latter result was somewhat surprising in light of the research of Horowitz (1961).

In regard to the failure to obtain a significant similarity effect in the free recall condition, it should be noted that the difference was in the expected direction. In addition, the study by Horowitz (1961) indicated that the superior free recall of highly similar material was evident only during the first five trials of his experiment. Furthermore, there are several differences between the Horowitz study and the one reported above. First, the material which Horowitz employed was different from that employed in the present study. Whereas the high similarity list in the present study was formed by arranging seven letters to form $10 \mathrm{CVCs}$, Horowitz arranged only four letters to form 12 CCCs. Thus, Horowitz's items were extremely similar. Second, Horowitz did not employ a paced recall procedure like that employed in the present study. Thus, Ss in his study had ample time to profit from the interitem relationships present in the material. Finally, it should be noted that Horowitz employed children as Ss, and age might have some unknown effect in such a situation.

\section{REFERENCES}

DEESE, J. Influence of inter-item associative strength upon immediate free recall. Psychological Reports, 1959, 5, 305-312.

HOROWITZ, L. M. Free recall and ordering of trigrams. Journal of Experimental Psychology, 1961, 62, 51-57.

UNDERWOOD, B. J. Studies of distributed practice: VII. Learning and retention of serial nonsense lists as a function of intralist similarity. Journal of Experimental Psychology, 1952, 44, 80-87. 